Article

\title{
Effects of the Power Supply Mode and Loading Parameters on the Characteristics of Micro-Arc Oxidation Coatings on Magnesium Alloy
}

\author{
Jian-tao Yao ${ }^{1, *}$, Sheng Wang ${ }^{2}$, Yong Zhou ${ }^{1}$ and Hui Dong ${ }^{1}$ \\ 1 School of Materials Science and Engineering, Xi'an Shiyou University, Xi'an 710065, China; \\ yzhou@xsyu.edu.cn (Y.Z.); donghui@xsyu.edu.cn (H.D.) \\ 2 State Key Laboratory of Gansu Advanced Non-ferrous Metal Materials, Lanzhou University of Technology, \\ Lanzhou 730050, China; shengwang@lut.cn \\ * Correspondence: jiantaoyao@xsyu.edu.cn; Tel.: +86-29-8838-2607
}

Received: 27 September 2020; Accepted: 29 October 2020; Published: 30 October 2020

\begin{abstract}
Micro-arc Oxidation (MAO) is a technology for non-ferrous metal surface treatment through growth ceramic coating in situ. To determine the influence of the power supply mode and the loading parameters on the film forming of magnesium alloy micro-arc oxidation processing, the different power supply modes of pulsed direct current DC, pulsed bipolar current (BC) and the pulsed with a discharge loop current (DLC) was used with MAO technology on the AZ91D magnesium alloy. The power load parameters were optimized. The average energy consumption was calculated. Results showed that the role of the negative voltage in the bipolar pulse power supply is to restrain the large arc tendency. Under the pulse power supply with a discharge loop, the current and energy consumption decreases with the increase of the discharge resistance at the same pulse parameters. The big arc phenomenon can be effectively avoided and the impact of load capacitance could be effectively avoided by using the pulse power supply with a discharge loop. Moreover, the processing of the micro-arc oxidation is stable, the arc point is uniform, the surface of the film is smooth, the hole is uniform and the coating is dense, and the film efficiency is improved effectively.
\end{abstract}

Keywords: micro-arc oxidation; load characteristics; power mode; average energy consumption; load parameters

\section{Introduction}

Micro-arc oxidation (MAO) is a novel surface engineering technique of forming ceramic coatings on some non-ferrous metals, such as $\mathrm{Mg}$, $\mathrm{Al}$, $\mathrm{Ti}$, etc., and their alloys. It is also known as anodic spark deposition or micro-arc discharge oxidation. The MAO method forms an excellent adhesion of ceramic coatings, which would effectively improve the surface properties, such as wear and corrosion resistance, electrical insulation, and thermal properties [1-6]. It is well-known that MAO technology has ease of controlling and is environmentally friendly. However, in fact, the MAO process is extremely complicated and combines the high voltage sparks and electrochemical oxidation [7-10].

Most of the present studies focus on the adjustment of process parameters to controlling the microstructure and properties of ceramic coatings [11,12]. On the one hand, the MAO process was main influenced by the non-electric parameters (solution, temperature, oxidation time, etc.) $[13,14]$. On the other hand, the electrical parameters (current density, voltage, frequency, duty cycle, etc.) have the greatest influence on the formation of metal ceramics during MAO processing [15-18]. Generally, the thickness of micro-arc oxidation coating will increase with the increase of voltage, duty ratio and current density, while its surface morphologies will get coarser and its hardness will decrease. However, there is no a detailed explanation for these phenomena. We give more attention to the supply 
of energy and ignore the characteristics of the load itself. Thus, the different power modes, direct current (DC), pulsed DC, pulsed bipolar current (BC) or alternative current (AC), were used to apply voltage for the MAO processing [19-21]. There were few reports on the formation and influence of the substrate characteristics during the Micro-arc Oxidation processing, which will reflect the power output waveform when the power is loaded. Furthermore, which kind of power voltage supply and the output waveform is more suitable for the MAO technology, stabilization, and energy efficiency is not clear. In particular, in the process of MAO surface treatment, there is a local big arc ablation phenomenon of sample [22]. Once this kind of local big arc phenomenon occurs, it will ablation sample matrix and the processing work piece were damaged.

In this study, the different power supply modes of pulsed direct current (DC) pulsed bipolar current (BC) were used with micro-arc oxidation technology on the AZ91D magnesium alloy. Based on the study of load characteristics under different waveforms, a micro-arc oxidation power supply mode with discharge loop current (DLC) was used to fabricate coatings on the AZ91D magnesium alloy. The effect of the power supply modes on the surface mophology, thickness, and corrosion resistance of the coatings were investigated. Then, the influence of the loading parameters on the surface morphology and efficiency of micro-arc oxidation coatings were studied in the mode of discharge loop current (DLC) to aim at improving the efficiency, reduce energy consumption, and avoid the local big arc ablation phenomenon.

\section{Materials and Methods}

\subsection{Substrate Materials and MAO Device}

Disk specimens $(\Phi 30 \mathrm{~mm} \times 8 \mathrm{~mm}$ ) of AZ91D alloy were used as the substrate. Prior to treatment, the substrate were polished with the $\mathrm{SiC}$ abrasive paper to grit of 1200 and then cleaned in the deionized water for $10 \mathrm{~min}$ and thoroughly dried in the air. The electrolyte containing $\mathrm{Na}_{2} \mathrm{SiO}_{3} 13 \mathrm{~g} / \mathrm{L}$, $\mathrm{KF} 12 \mathrm{~g} / \mathrm{L}, \mathrm{NaOH} 4 \mathrm{~g} / \mathrm{L}$. The 18-8 stainless steel plate with a thickness of $1 \mathrm{~mm}$ were used as the cathode. The electrolyte temperature during the experiment was maintained at about 25 to $40{ }^{\circ} \mathrm{C}$ using a water cooling system. The voltages were supplied by the pulse power supply system developed by Lanzhou University of Technology. The device possess various output modes and the frequency range is $200 \sim 1000 \mathrm{~Hz}$ and the pulse-time ratio of $\mathrm{t}_{\text {on }}$ could be adjusted from 5 to $95 \%$.

\subsection{MAO Coatings Preparation}

The pulse forms of pulsed direct current (DC), pulsed bipolar current (BC) and the pulsed with a discharge loop current (DLC) were used to prepare the MAO coatings respectively. The work frequency was set as $667 \mathrm{~Hz}$ (pulse period: $1500 \mu \mathrm{s}$ ) and the duty ratio (pulse width: $450 \mu \mathrm{s}$ ) was kept at 30\%. The negative pulse voltage of the pulsed bipolar current was set as $-40 \mathrm{~V}$. The supplied voltage loading method is shown in Figure 1. Firstly, the voltage increased from 0 to $150 \mathrm{~V}$ at the speed of $30 \mathrm{~V} / \mathrm{min}$. Then the speed decreased at $5 \mathrm{~V} / \mathrm{min}$ and $10 \mathrm{~V} / \mathrm{min}$. The test would be stopped if the large arc occur during the processing.

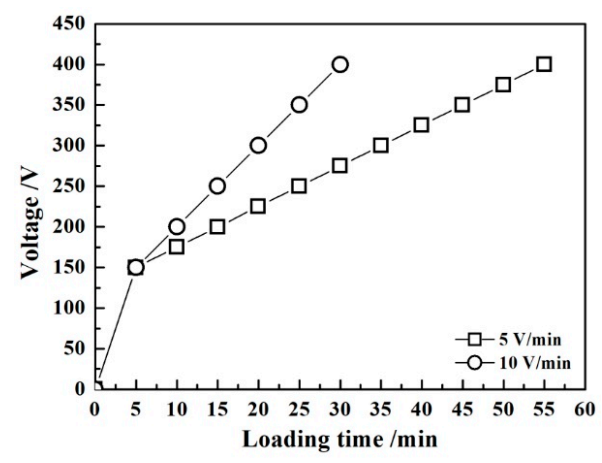

Figure 1. Voltage loading method for MAO experimental. 


\subsection{Characterization of the Coatings}

The surface morphology and the cross-sectional microstructure of the coatings were characterized by scanning electron microscopy (SEM, JSM6700: JEOL, Japan). Output waveform were recorded by oscillograph (Uni-tut 3200: UNI-TREND TECHNOLOGY CO., LTD, China). X-ray diffraction analysis was carried out to evaluate the phase compositions of the prepared samples. The film thickness was measured by TT260 digital cladding thickness meter (Beijing Era United Technology Co., Led, China). The pore size of the coatings was determined by analyzing SEM surface morphologies with an image analysis software (Image J, DT200: National Institutes of Health, USA). The corrosion resistance of the coatings was evaluated by electrochemical impedance spectroscopy (EIS, CHI600C: Midwest Science and Technology Led, Beijing, China) test using 3.5 wt.\% $\mathrm{NaCl}$ solution.

\subsection{Power Supply Mode with Discharge Loop Current (DLC)}

In this experiment, the pulse power mode with discharge loop current is adopted. The simplified topology of the power supply is shown in Figure 2. Open and shut off $\mathrm{Q}_{1}$ and $\mathrm{Q}_{2}$ alternately. Connect $\mathrm{Q}_{1}$ and output pulse voltage $\mathrm{V}_{1}$, to attain the requirements of micro-arc oxidation arc time. Turn on $\mathrm{Q}_{2}$ to discharge the load capacitance and provide cooling time. Where $I_{1}$ is the pulse current, $I_{2}$ is the discharge current, and $\mathrm{Q}_{2}$ constitutes the discharge loop of the load capacitor. When the switch $\mathrm{K}$ is closed, it discharges through the loop resistance. Because the resistance is small, the discharge time is short and the current is large, it is called complete discharge. When $\mathrm{K}$ is disconnected, the discharge time and peak current are adjusted by resistance $\mathrm{Rd}$. If the load voltage cannot be returned to zero before the pulse arrives, the discharge will be incomplete.

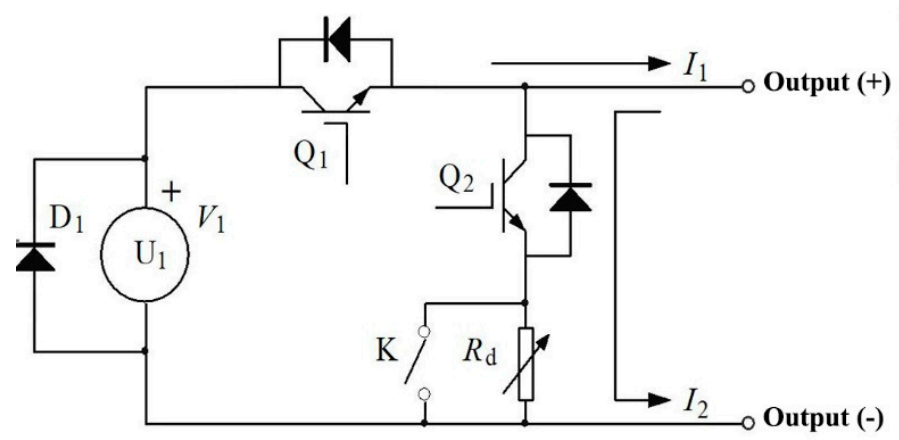

Figure 2. The simplified topology of the power supply Mode with Discharge Loop Current.

\section{Results and Discussion}

\subsection{Effect of the Power Supply Mode}

\subsubsection{Load Waveform Based on Different Power Supply Mode}

Figure 3 shows load waveform of the voltage (upper) and current (following) based on pulsed direct current (a), pulsed bipolar current (b) and the pulsed with a discharge loop current (c) power supply mode, respectively. Although the power supply output is square wave pulse voltage at the DC pulse mode, the actual voltage waveform is similar to a saw tooth waveform (Figure 3a). The voltage drops gradually during pulse output was shut down. The voltage waveform of the BC pulse mode is similar to the DC, and the negative pulse cycle is reversed with the positive pulse cycle as shown in Figure $3 \mathrm{~b}$. Besides, the voltage amplitude is less than the positive voltage due to the negative voltage being constant at $40 \mathrm{~V}$. Current waveform corresponded to the voltage pulse. Furthermore, the current peak value is huge when the voltage at the maximum, then it rapidly decreasing. It is quite indicated that the load present dramatically capacitive character result in the voltage waveform being like the capacity discharge during pulse output was shutdown. In the pulse form with discharge loop current 
(Figure 3c), the pulse voltage presents approximate square wave output. This is due to the alternating on and off of the pulse and discharge loop current, which eliminates the effect of the load capacitance.

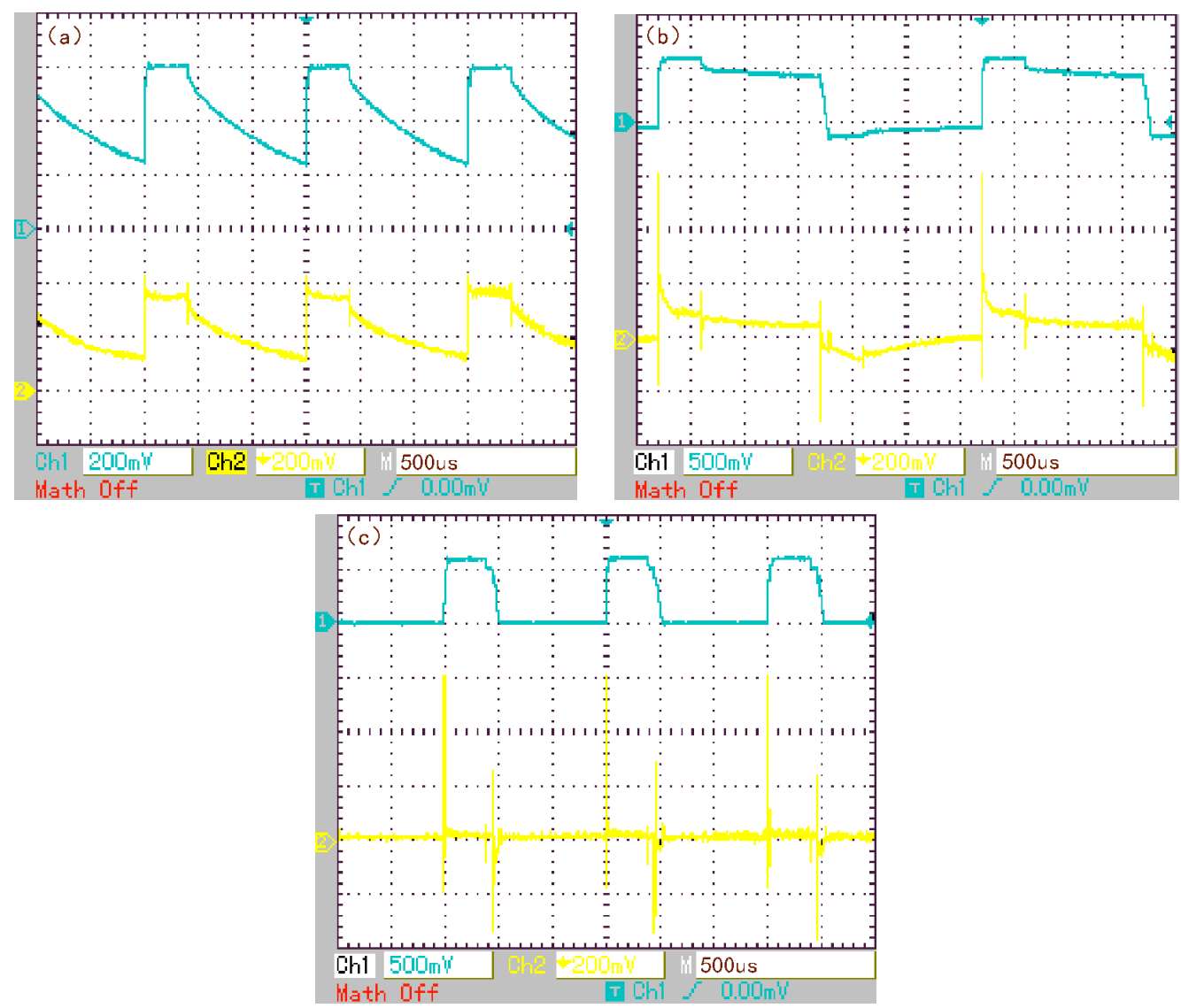

Figure 3. Load waveform of the voltage (upper) and current (following) based on pulsed direct current (a), pulsed bipolar current (b) and the pulsed with a discharge loop current (c) power supply mode.

\subsubsection{Effect of the Power Supply Mode on the Microstructure of Ceramic Coatings}

Figure 4 presents the surface morphology of the MAO coatings using pulsed direct current, pulsed bipolar current and the pulsed with a discharge loop current power supply mode, respectively. As observed from the surface morphology of the MAO coatings obtained at different power supply mode, the coatings surface is typically micro-porous structure and the pore size is about 1 to $4 \mu \mathrm{m}$. In particular, even though the frequency and the pulse radio was the same in the three cases, there are a mass of ablatives on the surface of MAO coatings as shown in Figure 4a which is due to the large discharge phenomenon under the pulse DC power supply mode. Also, micro-cracks can be seen in Figure $4 \mathrm{~b}$ formed by the pulse BC. In contrast, the surface morphology is smoother and there are no cracks based on the pulse DLC power supply mode (Figure 4c). During the formation of MAO coatings the spark discharges lead to melted, sintered, and localized high temperature according the pulse supply. It can be considered that the large arc phenomenon was caused by constant spark discharge supplied by constant voltage. Therefore, the large arc tendency appears in order from high to low is unipolar pulse, bipolar pulse, pulse form with discharge loop current in different pulse modes. It is considered that the temperature of near the location of micro-zone discharge is increased, because the ionization energy of the gas decreases with the increase of temperature, the surrounding area is more likely to produce micro-zone discharge, and the large arc is generated when this phenomenon continues. Thus, the large arc phenomenon will have self-reinforcing effect under a constant voltage. Therefore, micro-arc oxidation requires the power output waveform to be in the form of pulse to 
provide the necessary cooling time to discretize the arc. However, the load present dramatically capacitive character result in the load voltage is always higher than the arc starting voltage by the form of unipolar pulse. Although the output of the power supply is square wave type pulse, it is actually pulsating DC, which cannot provide the necessary cooling time, and the large arc tendency is serious. Under the bipolar pulse form, due to the negative voltage loading, the load voltage is forced to zero or negative voltage during the negative pulse period. Therefore, the load voltage drops faster than the unipolar pulse form, effectively reducing the large arc tendency. However, micro-arc oxidation with magnesium alloy as anode did not occur during the negative pulse period. Negative pulse can also cause corrosion of stainless steel electrode surface, electrolyte contamination, sample surface rust, solution temperature rise and other phenomena. The pulse form with the discharge loop current eliminates the effect of the load capacitance and forces the voltage to zero. The square wave pulse discretizes the arc, avoids the destructive effect of continuous arc on the workpiece, and effectively restrains the large arc phenomenon. The process is stable, the arc point is uniform, and the upper limit of working voltage and film thickness is raised to a certain extent.

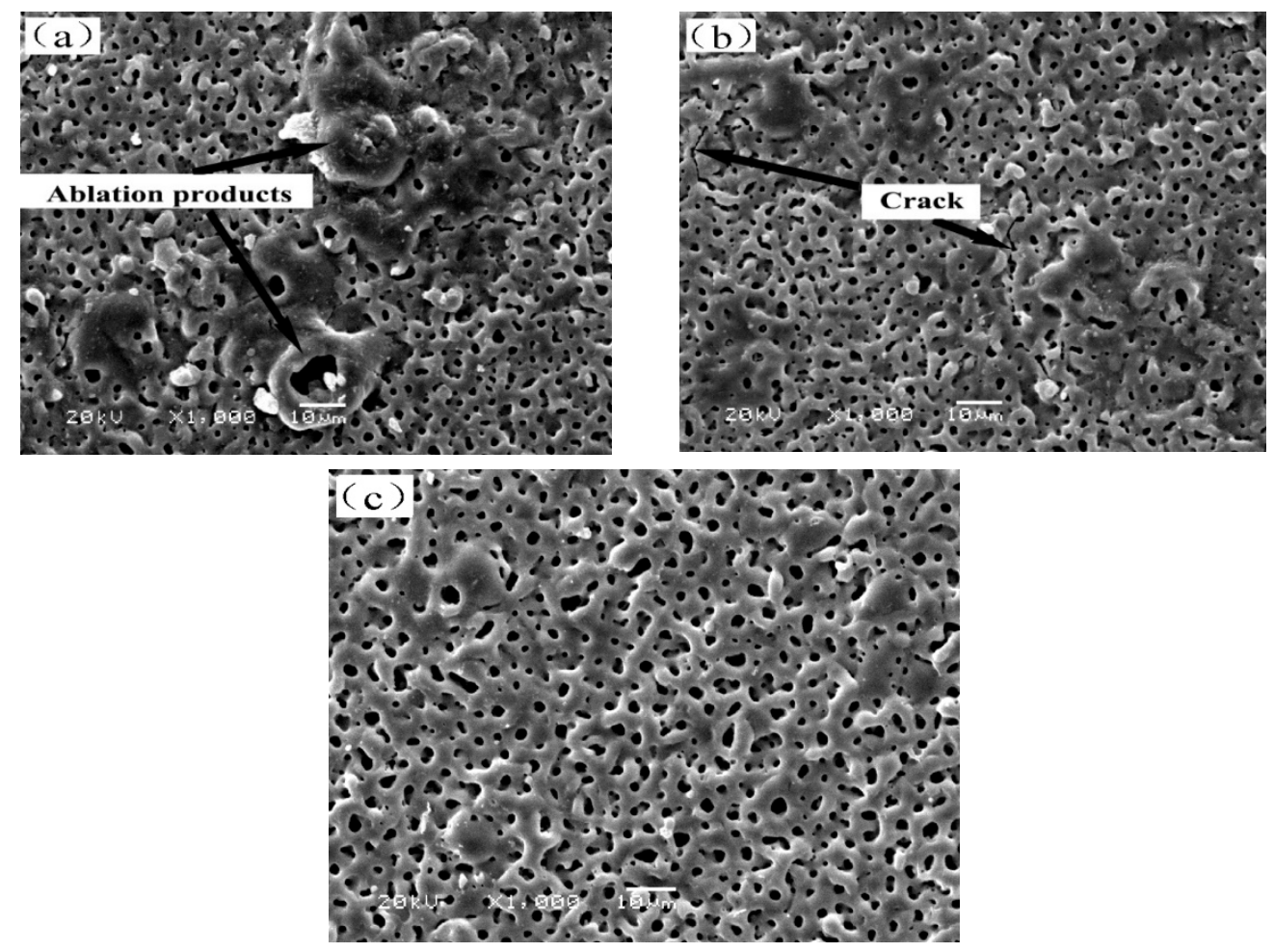

Figure 4. Surface morphology of MAO AZ91D Mg-alloy using pulsed direct current (a), pulsed bipolar current (b) and the pulsed with a discharge loop current (c) power supply mode.

The typical XRD patterns of the MAO coatings using pulsed bipolar current and the pulsed with a discharge loop current power supply mode are shown in Figure 5 with different color, respectively. It can be clearly found that the phase composition of the MAO ceramic coatings are mainly composed of $\mathrm{MgO}$, spinel $\mathrm{MgAl}_{2} \mathrm{O}_{4}$ and $\mathrm{Mg}_{2} \mathrm{SiO}_{4}$. Peaks related to the AZ91D alloy ( $\mathrm{Mg}$ and $\mathrm{Mg}_{17} \mathrm{Al}_{12}$ phases) are also observed in XRD spectra. It can be considered that the phase of $\mathrm{Mg}$ and $\mathrm{Mg}_{17} \mathrm{Al}_{12}$ are produced by the molten oxide sprayed onto the surface during micro-arc discharge and deposited on the surface of the coatings. Additionally, intensity of peaks corresponding to $\mathrm{MgO}$ phase is lower with the pulse of $\mathrm{BC}$ than the pulse of DLC. XRD studies demonstrate that in the case of bipolar current pulse, the reaction temperature may be higher, and repeated remelting and thermal etching makes the oxidation product more complex. 


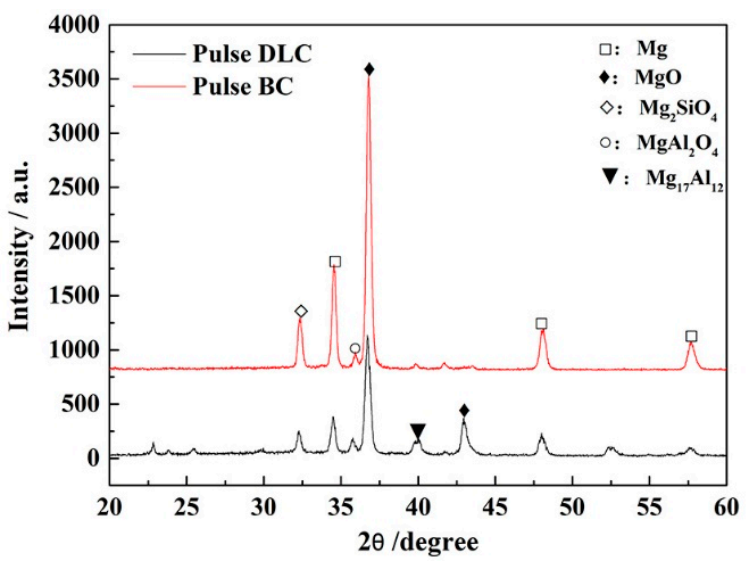

Figure 5. The XRD patterns of the MAO coatings using pulsed bipolar current and the pulsed with a discharge loop current power supply mode.

\subsubsection{Thickness of Ceramic Coatings}

Figure 6 shows the cross-sectional morphology of MAO coatings in power supply mode of pulse bipolar current Figure 6a and pulse with a discharge loop current Figure 6b. It clearly that the coatings with DLC pulse mode is compact and the interface between the coating and subctrate cannot be observed obviously in Figure 6a. However the coatings with BC pulse mode is un-uniform and loose as shown in Figure $6 \mathrm{~b}$. The pores and loose coating can be obviously observed from the cross-sectional photograph of the MAO coating with power supply mode of pulse bipolar current. The finally thickness of the coatings produced by different power supply mode of pulse bipolar current and pulse with a discharge loop current are almost up to $20 \mu \mathrm{m}$. The coatings growth rate curve are shown in Figure 7. It is obvious that the thickness of the coating formed by pulse DLC increased faster than the formed by pulse BC. It should be noted that the coating growth rate keeps almost consistent with that two type of power supply. However, in pulse DLC, the growth rate is slowly in treatment time at 25 to $30 \mathrm{~min}$. Instead, coating thickness grow faster by pulse $\mathrm{BC}$ at the same stage. As mentioned above, when the voltage increased and the oxidation time prolonged, the pulse $\mathrm{BC}$ is unable to provide adequate cooling time for MAO processing so that the constant high temperature lead to large arc phenomenon then make the coating thickness increased faster.
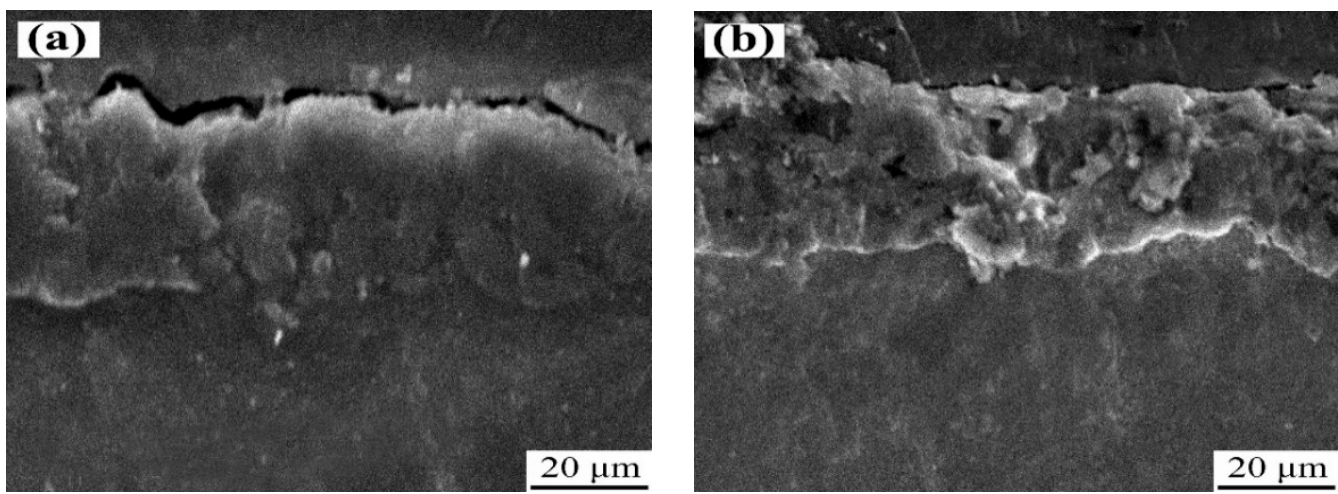

Figure 6. The cross-section morphology of MAO coatings in power supply mode of pulse bipolar current (a) and pulse with a discharge loop current (b). 


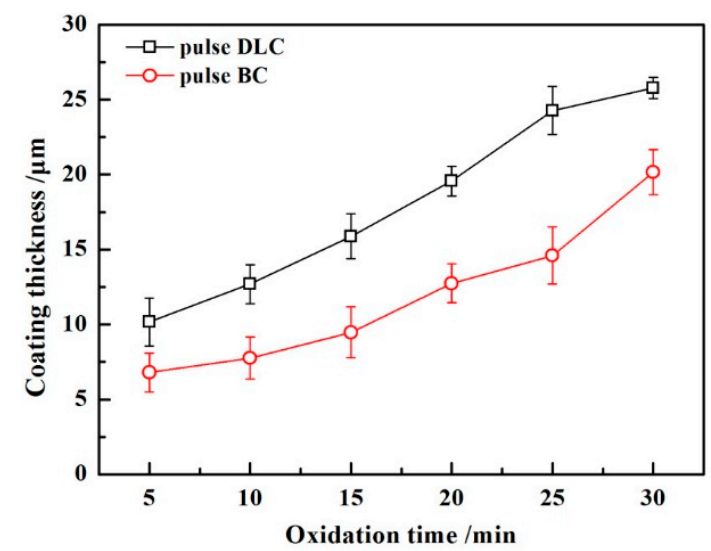

Figure 7. The growth rate of MAO coatings in power supply mode of pulse bipolar current and pulse with a discharge loop current.

\subsubsection{Electrochemical Corrosion Analysis}

Figure 8 shows the corrosion resistance properties of the Mg-alloy substrate and the MAO coatings prepared at the two pulse power supply mode were measured by potential dynamic polarization test. According to the Tafel fitting method, the more positive the corrosion potential, the smaller the corrosion current density, the greater the polarization resistance and the better the corrosion resistance of the sample. It can be clearly seen that the corrosion resistance was improved by surface treatment $\mathrm{MAO}$ at the two pulse power supply mode. The corrosion potential represents the corrosion tendency, the Ecorr of the MAO coating shifts positively $246 \mathrm{mV}$ and $349 \mathrm{mV}$, respectively, under the different power supply mode, so the corrosion tendency of the sample by pulse BC easier than the sample by pulse DLC. Furthermore, corrosion current and polarization resistance represent corrosion velocity. It is can be observed that the corrosion current of coating by pulse DLC is lower than it by pulse $\mathrm{BC}$. Thus, the corrosion velocity of the sample by pulse BC fasterer than the sample by pulse DLC. The results is mainly due to the MAO coating is loose and the porosity is large in the pulse BC mode.

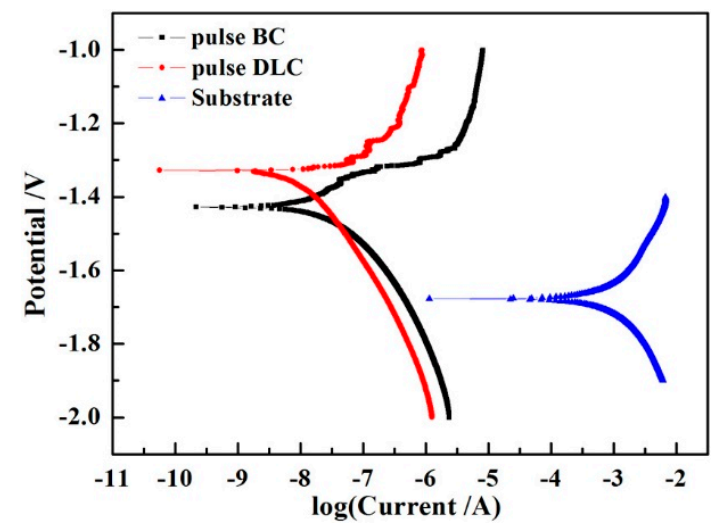

Figure 8. Polarization curves of AZ91D Mg-alloy substrate, MAO coatings by pulse bipolar current and pulse with a discharge loop current power supply mode.

\subsection{Comparasion with MAO Coatings Obtained by Different Loading Parameters}

\subsubsection{Surface Morphology}

Figure 9 illustrates the surface morphologies of the coatings fabricated by the voltage loading speed was $10 \mathrm{~V} / \mathrm{min}$ and $5 \mathrm{~V} / \mathrm{min}$, respectively, and the pulse with a discharge loop current power supply mode. It could be observed that tiny micropores distributed uniformly on the coating. This can be attributed to the discharge loop providing such sufficient cooling time that lead the temperature 
and reaction intensity decreases. Mini hole also can be observed in the big hole, because the voltage is increased gradually, result in discharge grow up and vanish one after another, and a new hole is formed on the previously generated hole. Compared with the two photographs, it shows that the average micropore size reduced with the loading value decreased. The percentage of the average micropore size on the coatings was presented in Figure 10. It is obviously that the coating under the loading level at $10 \mathrm{~V} / \mathrm{min}$ is larger than that loading level at $5 \mathrm{~V} / \mathrm{min}$. With the voltage increments increase, the arc discharge is intensified under the same condition. Therefore, the average micropore size increased. When the loading level at $5 \mathrm{~V} / \mathrm{min}$, the average micropore size less than $2.5 \mu \mathrm{m}$ for $81.8 \%$. while the $20 \%$ of the micropore size is between $2.5-3 \mu \mathrm{m}$ under the loading level at $10 \mathrm{~V} / \mathrm{min}$. This demonstrates that a small voltage increments make for formation a dense and uniform coatings.
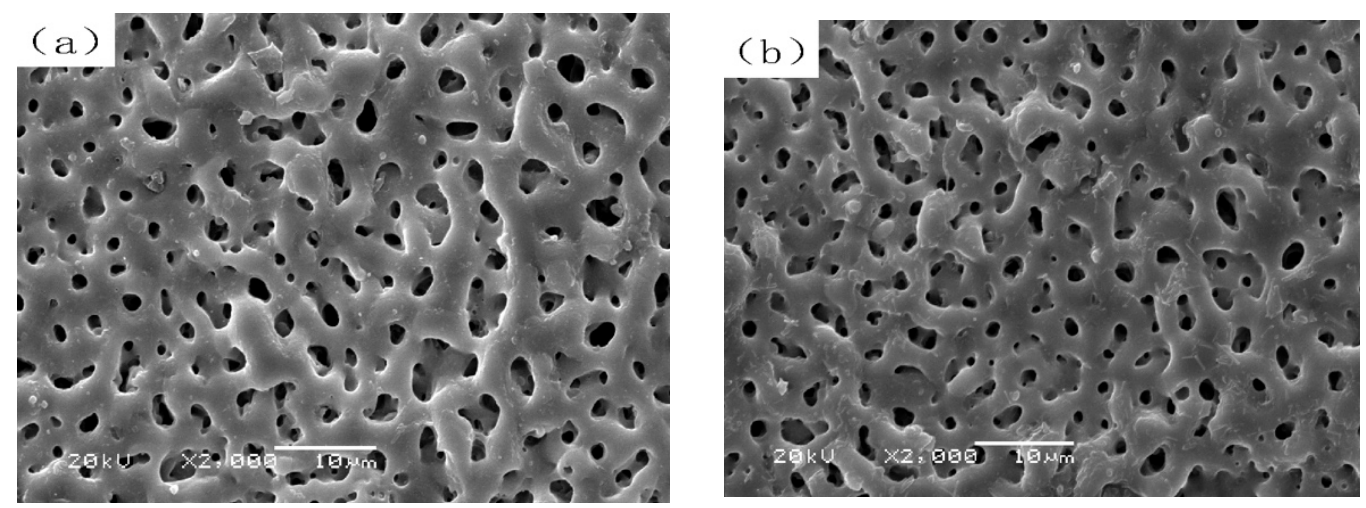

Figure 9. Surface morphology of MAO AZ91D Mg-alloy coatings by the voltage loading speed was: (a) $10 \mathrm{~V} / \mathrm{min}$ and (b) $5 \mathrm{~V} / \mathrm{min}$.

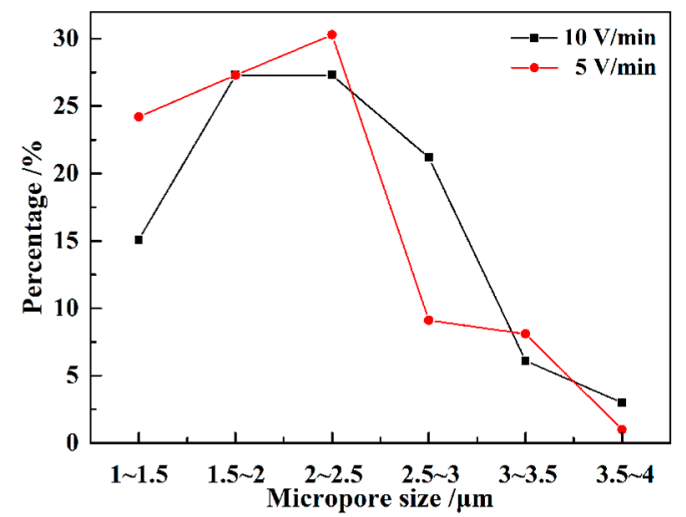

Figure 10. Percentage of the average micropore size on the coatings under the loading level at $10 \mathrm{~V} / \mathrm{min}$ and $5 \mathrm{~V} / \mathrm{min}$.

\subsubsection{Coating Formation Efficiency}

The energy consumed is different with different loading parameters. The power increase with the voltage increment increase during the same time. Because within the same time and under the same load, the greater the voltage increment, the greater the reaction intensity, the greater the current, then the greater the power. During the processing of pulse discharge loop power supply mode, MAO coating growth mainly occurred in the positive impulse. Thus, the energy can be expressed as a single pulse energy as follows:

$$
\mathrm{W}_{\mathrm{i}} \approx \mathrm{u}_{\mathrm{i}} \times \mathrm{i}_{\mathrm{i}} \times \mathrm{t}_{\mathrm{on}}
$$

where $\mathrm{W}_{\mathrm{i}}, \mathrm{u}_{\mathrm{i}}$, and $\mathrm{i}_{\mathrm{i}}$ represent the impulse energy, average anodic voltage, and average current density, respectively. Additionally, $t_{\text {on }}$ represent the anodic and related to the frequency and duty ratio. 
The relationship of thickness of MAO coatings and electric power with oxidation time at the loading level was $10 \mathrm{~V} / \mathrm{min}$ and $5 \mathrm{~V} / \mathrm{min}$ are shown in Figure 11. The growth curve of the coating almost coincides with the power at the loading level was $10 \mathrm{~V} / \mathrm{min}$. However, the growth curve of the coating higher than the power at the loading level was $5 \mathrm{~V} / \mathrm{min}$. It is indicated that in the early stage of treatment, small voltage increment has low energy consumption and high efficiency. When the coating thickness is up to a same value, the treatment time increased significantly under the loading level was $5 \mathrm{~V} / \mathrm{min}$. Although the constant voltage increment is small, the current will be relatively small, but the loading time is prolonged, and the energy will increase with the accumulation of time. Thus, the energy consumption is larger than the case of the loading level was $10 \mathrm{~V} / \mathrm{min}$. Therefore, the voltage increment should be small first and then large, which will be beneficial to improve efficiency and reduce energy consumption at the termination voltage is equal.

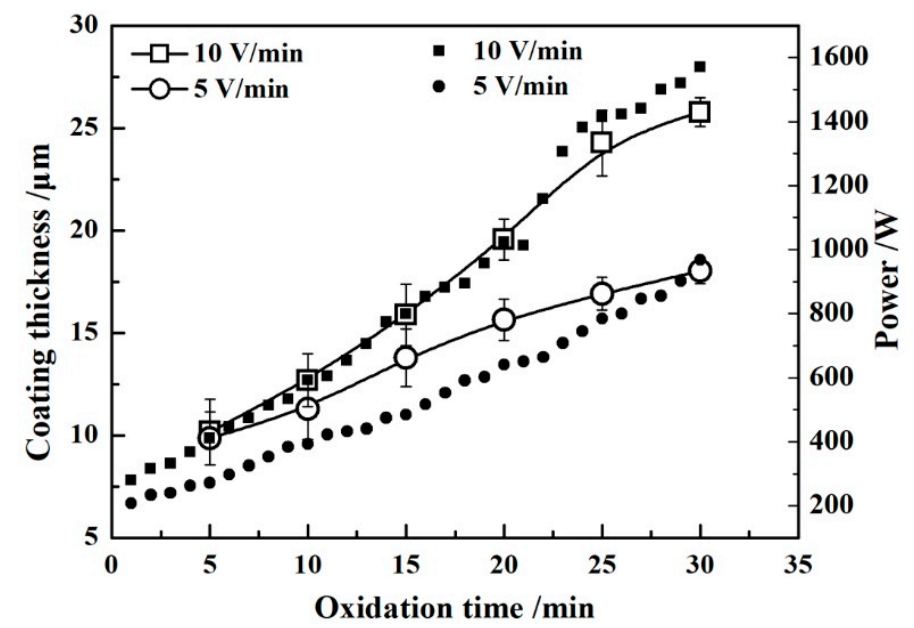

Figure 11. The thickness of MAO coatings and electric power with oxidation time at the loading level was $10 \mathrm{~V} / \mathrm{min}$ and $5 \mathrm{~V} / \mathrm{min}$.

\section{Conclusions}

The pulse modes of pulsed direct current (DC), pulsed bipolar current (BC) and the pulsed with a discharge loop current (DLC) were used to prepare the MAO coatings on AZ91D Mg alloys. The results show that the load's present dramatically capacitive character results in the voltage waveform capacity discharge during pulse output being shut down. The effect of the load capacity can be effectively eliminated through pulse and discharge loop current alternating on and off by pulse discharge loop current power supply, which provide the necessary cooling time made the spark discharge discretize. Therefore, the process is stable, the surface morphology is uniform, and the upper limit of working voltage and film thickness is raised to a certain extent. In addition, the thickness and corrosion resistance of coatings by pulse DLC power supply is better than pulse BC power supply mode. Under the same pulse with discharge loop current power supply mode, the loading method has a remarkable influence on MAO processing. The results indicated that a small voltage increments make for formation a dense and uniform coatings. While the voltage increment should be small first and then large, which will be beneficial to improve efficiency and reduce energy consumption at the termination, voltage is equal.

Author Contributions: Conceptualization, J.-t.Y. and S.W.; data curation, H.D.; formal analysis, J.-t.Y.; investigation, H.D.; methodology, S.W.; resources, S.W.; writing—original draft, J.-t.Y.; writing—review \& dditing, Y.Z. All authors have read and agreed to the published version of the manuscript.

Funding: The present project is financially supported by the Fund for the National Natural Science Foundation of China (Grant No. 52001254). Materials Science and Engineering of Provincial Advantage Disciplines in Xi'an Shiyou University (No. YS37020203), and the Special Research Program Department of Education of Shaanxi Province (No. 17JK0612). 
Acknowledgments: The guidance and help of State Key Laboratory of Gansu Advanced Non-ferrous Metal Materials of Lanzhou University of Technology are greatly acknowledged.

Conflicts of Interest: The authors declare no conflict of interest.

\section{References}

1. Li, X.J.; Zhang, M.; Wen, S.; Mao, X.; Huo, W.G.; Guo, Y.Y.; Wang, Y.X. Microstructure and wear resistance of micro-arc oxidation ceramic coatings prepared on 2A50 aluminum alloys. Surf. Coat. Technol. 2020, 394, 125853. [CrossRef]

2. Wang, W.Z.; Feng, S.S.; Li, Z.M.; Chen, Z.G.; Zhao, T.Y. Microstructure and properties of micro-arc oxidation ceramic films on AerMet100 steel. J. Mater. Res. Technol. 2020, 9, 6014-6027. [CrossRef]

3. Zhang, K.; Yu, S.R. Preparation of wear and corrosion resistant micro-arc oxidation coating on 7N01 aluminum alloy. Surf. Coat. Technol. 2020, 388, 125453. [CrossRef]

4. Muhaffel, F.; Cimenoglu, H. Development of corrosion and wear resistant micro-arc oxidation coating on a magnesium alloy. Surf. Coat. Technol. 2019, 357, 822-832. [CrossRef]

5. Bai, L.J.; Kou, G.; Zhao, K.; Chen, G.T.; Yan, F.X. Effect of in situ micro-arc oxidation coating on the galvanic corrosion of AZ31Mg coupled to aluminum alloys. J. Alloys Compd. 2019, 775, 1077-1085. [CrossRef]

6. Li, Z.Y.; Cai, Z.B.; Cui, Y.; Liu, J.H.; Zhou, M.H. Effect of oxidation time on the impact wear of micro-arc oxidation coating on aluminum alloy. Wear 2019, 426-427, 285-295. [CrossRef]

7. Zhao, Z.Q.; Pan, Q.L.; Yan, J.K.; Ye, J.; Liu, Y.R. Direct current micro-arc oxidation coatings on Al-Zn-Mg-Mn-Zr extruded alloy with tunable structures and properties templated by discharge stages. Vacuum 2018, 150, 155-165. [CrossRef]

8. Cengiz, S.; Azakli, Y.; Tarakci, M.; Stanciu, L.; Gencer, Y. Microarc oxidation discharge types and bio properties of the coating synthesized on zirconium. Mater. Sci. Eng. C 2017, 77, 374-383. [CrossRef]

9. Cui, L.Y.; Zeng, R.C.; Guan, S.K.; Qi, W.C.; Zhang, F. Degradation mechanism of micro-arc oxidation coatings on biodegradable Mg-Ca alloys: The influence of porosity. J. Alloys Compd. 2017, 695, 2464-2476. [CrossRef]

10. Kaseem, M.; Min, J.H.; Ko, Y.G. Corrosion behavior of Al- $1 \mathrm{wt} \% \mathrm{Mg}-0.85 \mathrm{wt} \% \mathrm{Si}$ alloy coated by micro-arc-oxidation using $\mathrm{TiO}_{2}$ and $\mathrm{Na}_{2} \mathrm{MoO}_{4}$ additives: Role of current density. J. Alloys Compd. 2017, 723, 448-455. [CrossRef]

11. Kamal Jayaraj, R.; Malarvizhi, S.; Balasubramanian, V. Optimizing the micro-arc oxidation (MAO) parameters to attain coatings with minimum porosity and maximum hardness on the friction stir welded AA6061 aluminium alloy welds. Defence Technol. 2017, 13, 111-117. [CrossRef]

12. Pan, Y.K.; Wang, D.G.; Chen, C.Z. Effect of negative voltage on the microstructure, degradability and in vitro bioactivity of microarc oxidized coatings on ZK60 magnesium alloy. Mater. Lett. 2014, 119, 127-130. [CrossRef]

13. Wu, G.Q.; Zhao, D.C.; Lin, X.; Liu, J.B.; Ji, X.Y. Investigation of an environmentally friendly coloring coating for magnesium-lithium alloy micro-arc oxidation. Surf. Interfaces 2020, 20, 100513. [CrossRef]

14. Kaseem, M.; Hussain, T.; Rehman, Z.U.; Ko, Y.G. Stabilization of AZ31 Mg alloy in sea water via dual incorporation of $\mathrm{MgO}$ and $\mathrm{WO}_{3}$ during micro-arc oxidation. J. Alloys Compd. 2021, 853, 157036. [CrossRef]

15. Zhang, J.W.; Fan, Y.Z.; Zhao, X.; Ma, R.; Du, A.; Cao, X.M. Influence of duty cycle on the growth behavior and wear resistance of micro-arc oxidation coatings on hot dip aluminized cast iron. Surf. Coat. Technol. 2018, 337, 141-149. [CrossRef]

16. Wang, P.; Wu, T.; Xiao, Y.T.; Zhang, L.; Pu, J.; Cao, W.J.; Zhong, X.M. Characterization of micro-arc oxidation coatings on aluminum drillpipes at different current density. Vacuum 2017, 142, 21-28. [CrossRef]

17. Yang, X.; Wang, W.L.; Ma, W.J.; Wang, Y.; Liu, S.F.; Tang, H.P. Corrosion and wear properties of micro-arc oxidation treated Ti6Al4V alloy prepared by selective electron beam melting. Trans. Nonfer. Metals Soci. China 2020, 30, 2132-2142. [CrossRef]

18. Dai, W.B.; Li, C.Y.; He, D.; Jia, D.W.; Zhang, Y.M.; Tan, Z. Influence of duty cycle on fatigue life of AA2024 with thin coating fabricated by micro-arc oxidation. Surf. Coat. Technol. 2019, 360, 347-357. [CrossRef]

19. Bai, L.J.; Dong, B.X.; Chen, G.T.; Xin, T.; Wu, J.N.; Sun, X.D. Effect of positive pulse voltage on color value and corrosion property of magnesium alloy black micro-arc oxidation ceramic coating. Surf. Coat. Technol. 2019, 374, 402-408. [CrossRef]

20. Ly, X.N.; Yang, S. Influence of current mode on microstructure and corrosion behavior of micro-arc oxidation (MAO) biodegradable Mg-Zn-Ca alloy in Hank's solution. Surf. Coat. Technol. 2019, 358, 331-339. [CrossRef] 
21. Li, G.Q.; Wang, Y.P.; Qiao, L.P.; Zhao, R.F.; Zhang, S.F.; Zhang, R.F. Preparation and formation mechanism of copper incorporated micro-arc oxidation coatings developed on Ti-6Al-4V alloys. Surf. Coat. Technol. 2019, 375, 74-85. [CrossRef]

22. Tran, Q.P.; Kuo, Y.C.; Sun, J.K.; He, J.L.; Chin, T.S. High quality oxide-layers on Al-alloy by micro-arc oxidation using hybrid voltages. Surf. Coat. Technol. 2016, 303, 61-67. [CrossRef]

Publisher's Note: MDPI stays neutral with regard to jurisdictional claims in published maps and institutional affiliations.

(C) 2020 by the authors. Licensee MDPI, Basel, Switzerland. This article is an open access article distributed under the terms and conditions of the Creative Commons Attribution (CC BY) license (http://creativecommons.org/licenses/by/4.0/). 